Thorax (1954), 9, 198.

\title{
AN ANATOMICAL EXPLANATION OF THE FORMATION OF BUTTERFLY SHADOWS*
}

\author{
BY \\ G. HERRNHEISER AND K. F. W. HINSON \\ From the Connaught Hospital, Walthamstow, St. Margaret's Hospital, Epping, and the London Chest Hospital
}

(RECEIVED FOR PUBLICATION DECEMBER 21, 1953)

Butterfly or batswing shadows are perihilar opacities of a particular shape. They were observed by early authors in cases of pulmonary oedema (Day, Sisson, and Vogt, 1929; Coe and Otell, 1932; Roubier and Plauchu, 1933). Later details of the radiological appearances are described, variations noted, and several explanations of the pathogenesis suggested (Zdansky, 1933; Roubier and Plauchu, 1934; Lelong and Bernard, 1937; Roubier, 1938; Werkenthin, 1939, and others). The term " butterfly" density was introduced by Nessa and Rigler (1941) and the term "batswing" shadow by Hodson (1950).

\section{The Radiological Features}

In typical examples the radiological features are as follows: (a) In postero-anterior views (Figs. $1 \mathrm{a}, 2 \mathrm{~b}, 3 \mathrm{a}, 4)$ the shadows are bilateral, perihilar, almost symmetrical and extend from the hilum towards the periphery of the lung field but never reach it. (b) The apical and basal areas and a lateral zone of 2 to $4 \mathrm{~cm}$. remain translucent. Such clear marginal zones are characteristic. (c) There is frequently a waist-like indentation at the edge of the opacities which accentuates the resemblance to wings and often corresponds with an interlobar fissure (Figs. 1a, 3b). (d) In the upper lobes there is often translucent lung visible between the mediastinum and the butterfly density (Fig. 1a). The analogous zones of the middle and lower lobes are obscured by the heart shadow in most cases. (e) The edge of the shadow may be well marked, but commonly it is poorly defined. Poor definition may be caused by respiratory movements as the patients are frequently dyspnoeic. $(f)$ The butterfly opacities are often streaky or blotchy, but may consist of a diffuse cloudiness (Fig. 2a) or a mass of confluent patches.

\footnotetext{
* Based on a paper read before the International Congress of Radiology, Copenhagen, July, 1953.
}

In lateral views (Figs. 1b, 2b) the shadows occup $\frac{\mathbb{D}}{\mathbb{P}}$ the central part of the lung fields with transluce peripheral zones anteriorly and posteriorly. In the region of interlobar fissures an indentation of cleâr lung can occasionally be observed.

Deviations from the typical descriptions are frequent and make the diagnosis more difficult. The occur if the underlying lesion is unequally distribute The shadow may be present only in one lung (Fig. $3 b$ ), one lobe, or even one segment, or it may van in degree from side to side or even from lobe lobe.

The typical appearances may also be altered by the coexistence of complications such as hypostatic pulmonary oedema, pneumonia (Fig. 4), tuberc. losis, infarction, or pleural effusion. Such lesio often obscure the basal or peripheral parts of tre lung fields so that the characteristic translucence these marginal zones is lost.

The character of the opacity varies with the extent and the phase of development of the unde? lying lesion. With advanced cases most of the lobules in the affected area are filled and the shado is almost homogeneous (Fig. 2a). A mottled appearance is given if groups of aerated and opaque alveoli are intermingled as may happen at the onset or resolution of the process. The clearance may be rapid (Figs. 3b, 3c), and usually begins at the periphery and advances towards the hilum. Howe ever, in several cases we have observed it to occur the opposite direction so that a mottled, ribbon-like residue of the shadow, abutting the clear peripherष, persisted for a number of days.

The formation of typical and atypical butterfly opacities should be explicable on the basis of pathological findings. Kerley (1950) also expects an anatomical elucidation. However, the literature does not yield a satisfactory explanation. 


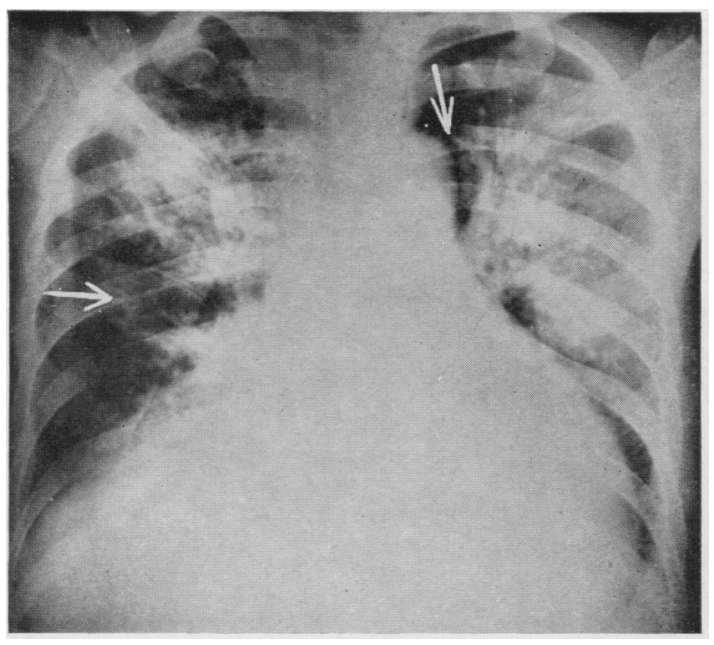

Fig. la

\section{Fig. 2a}

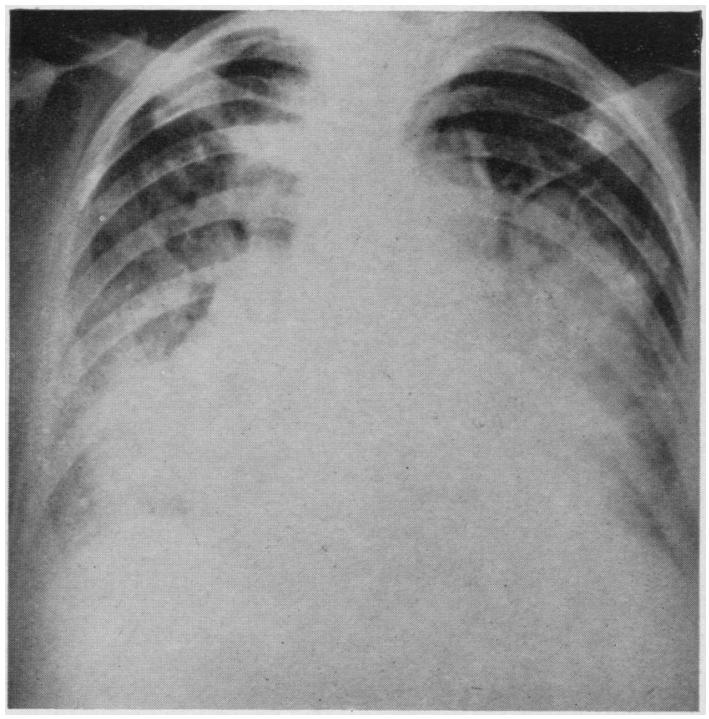

FIGs. $2 a$ and $b$.-Large butterfly shadow, blotchy and streaky in the right upper lobe, but almost homogeneous in the left upper surrounded by a translues. The centrally localized lopacily is of hyperparathyroidism with extensive renal calcifications and hypertension. Past history of toxaemia in pregnancy. Parahypertension. Past history of toxaemia in pregnancy. Para-
thyroid tumour removed. Admitted with hypertensive heart thyroid tumour removed. Admitted with hypertensive heart
failure which responded well to treatment. There was complete radiological clearance of the lungs.
Figs. $1 a$ and $b$.-Typical butterfly shadow 13 days before death Note translucency between mediastinum and opacity in left lung (arrow) and interlobar clear zone indenting opacities in right lung (arrow). Central localization is evident from Fig. $1 b$ right lung (arrow). Central localization is evident from Fig. $1 b$. The butterfly opacity almost disappeared before death, but a
right basal consolidation developed. For total section of right lung see Fig. 16. From a case of chronic nephritis, malignan hypertension, and congestive heart failure. Blood pressure $245 / 145 \mathrm{~mm}$. Hg. Blood urea $52 \mathrm{mg}$. rising to $285 \mathrm{mg}$. $100 \mathrm{ml}$. before death.

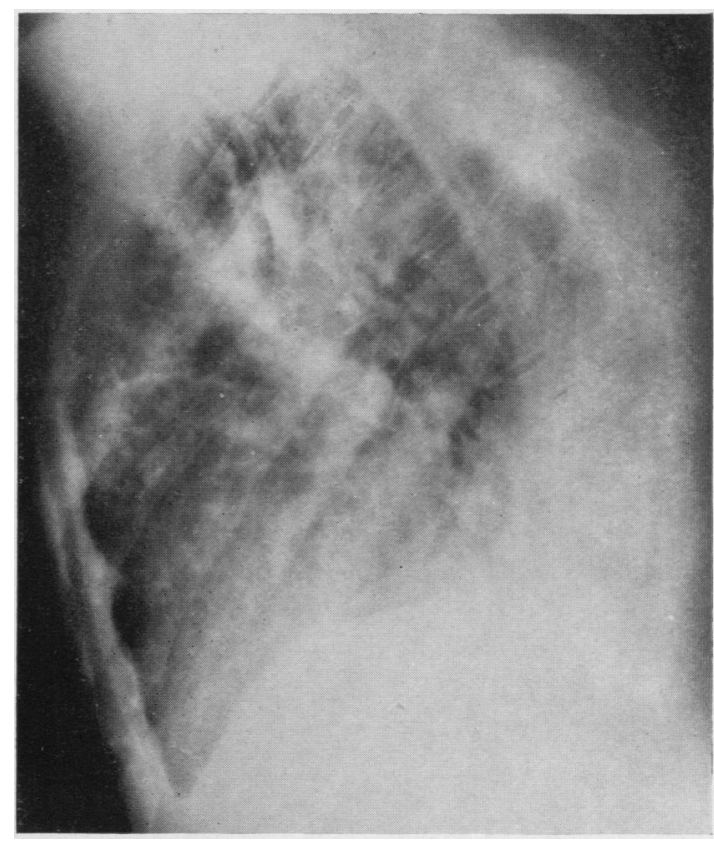

Fig. Ib

Fig. 2b

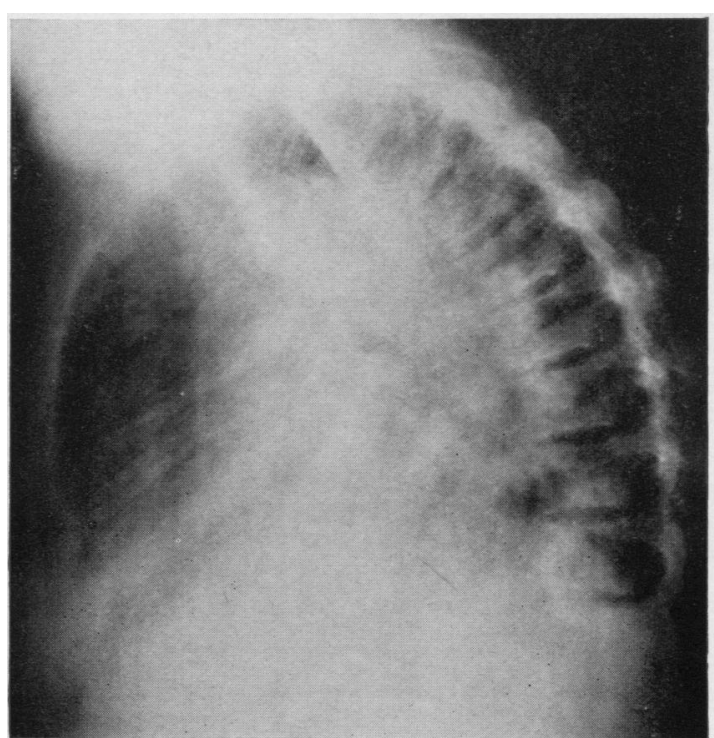


Fig. $3 \mathbf{a}$

Fig. 3b

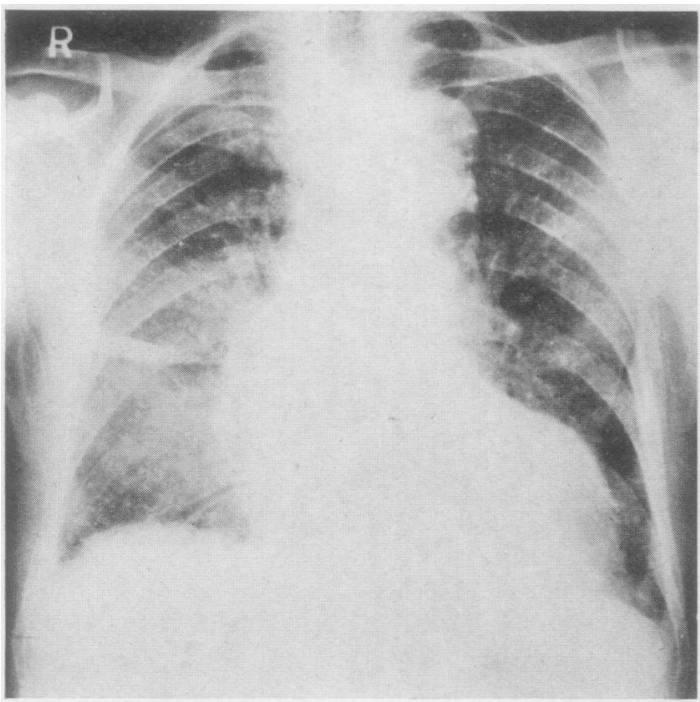

FIGs. $3 a, b$, and $c$.-In (a) no abnormalities in lungs; horizontal fissure visible as hairline. Hypertrophy and dilatation of left fissure visible as hairline. Hypertrophy and dilatation of left
ventricle. (b) One day later during an attack of cardiac asthma. ventricle. (b) One day later during an attack of cardiac asthma. Marked butterfly shadow in right lung, interlobar effusion in
horizontal fissure, dilatation of left ventricle considerably
increased. (c) Two days later : the butterfly opacity and the increased. (c) Two days later: the butterfly opacity and the interlobar effusion have completely cleared, the horizontal fissure reappeared as hairline, heart enlargement unchanged. From a case of acute retention of urine due to chronic prostatic obstruction. Blood pressure $190 / 80 \mathrm{~mm}$. Hg. Blood urea $145 \mathrm{mg}$./ $100 \mathrm{ml}$. on admission falling to normal after suprapubic cystotomy. Attack of pulmonary oedema $(b)$ was thought to be tomy. Attack of pulmonary
due to left ventricular failure.

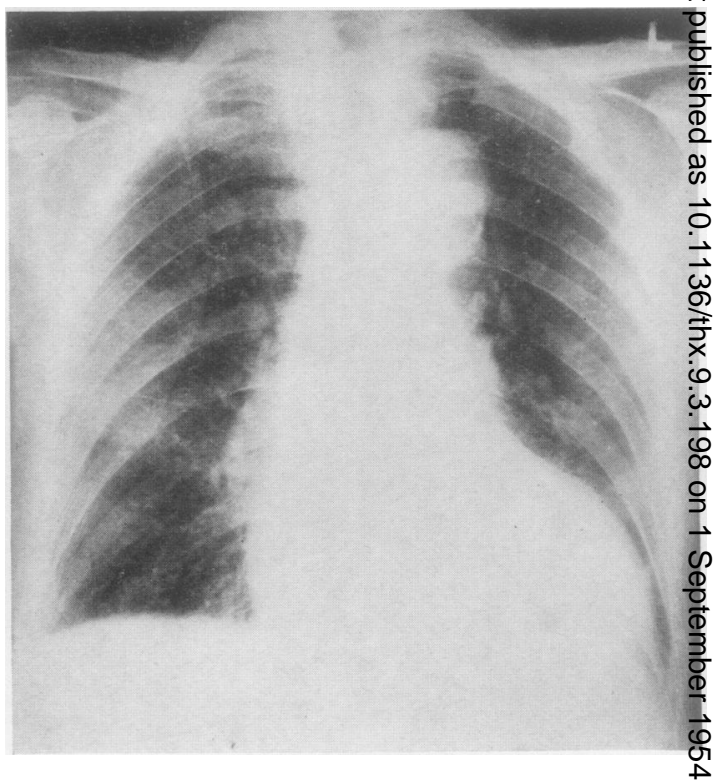

Fig. 3c

음

FIG. 4-Five days before death butterfly shadow combined with consolidation of bronchopneumonic character in right uppe lobe. Whole lung section (left) is shown in Fig. 15. From a case of chronic nephritis and malignant hypertension. Blood pressure 235120 . Blood urea $190 \mathrm{mg} .100 \mathrm{ml}$.

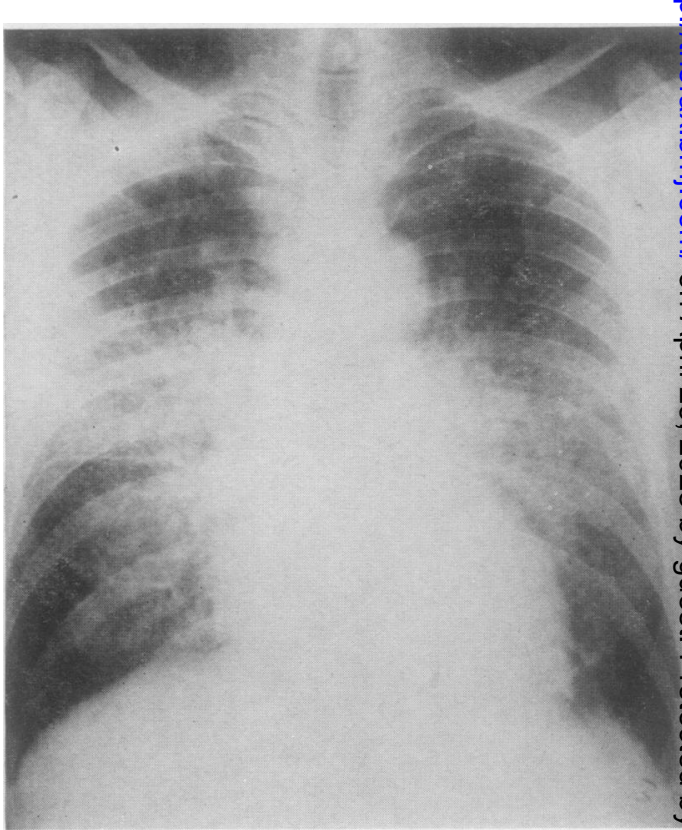




\section{Morbid ANATOMY}

Detailed necropsy findings in cases of butterfly shadows are scanty. Roubier and Plauchu (1933 and 1934) described three cases in which there was advanced chronic nephritis and hypertrophy of the left ventricle. There was generalized oedema of the lungs in one case and oedema of the lower lobes in the others. Histological sections of one of the latter cases showed that some of the alveoli were distended by oedema while others were filled with haemorrhagic fluid in which were strands of fibrin.

The presence of serous fluid within the alveoli was reported by Nessa and Rigler (1941), who had examined some cases with butterfly shadows among other types of pulmonary oedema.

The first complete description of the pathology in this type of case was given by Doniach (1947), who emphasized the central distribution of the oedema. Macroscopically there was widespread solid oedema in which the lungs were gelatinous and somewhat rubbery, yielding frothy liquid only when firm pressure was applied. Microscopically in two of the cases there was a striking fibrinous exudate and in the other two this change occurred in patches in the midst of a predominating albuminous exudate.

The pathological changes in two further cases are given by Hodson (1950). One had suffered longstanding hypertension with cerebral oedema, and the lungs were congested, oedematous, and consolidated in a butterfly distribution. In a second case (polyarteritis nodosa) the changes were most severe in the right lung, which was distended by oedema fluid which had a butterfly arrangement. There was a peripheral zone about $1 \mathrm{~cm}$. deep which was relatively normal.

In the necropsy records of two of the cases observed by Santé and Wyatt (1951) the changes in the lungs were widespread or generalized and consisted of hyaline membrane closely applied to the alveolar walls.

The scarcity of morbid anatomical descriptions of such transient lesions as produce butterfly shadows is understandable. The oedema may disappear before death or become generalized. More commonly perhaps it is associated with terminal bronchopneumonia, pleural effusions, and other complications which obscure the characteristic appearances both in radiographs and necropsy specimens. The conventional dissection of a lung at necropsy does not display the typical distributions.

\section{Pathogenesis}

There is little doubt that in most cases oedema in central parts of the lung is the underlying con- dition of butterfly lesions (Nessa and Rigler, 1941 ; Doniach, 1947). The aetiology of the oedema is still under discussion. Among its causes uraemia and renal azotaemia, left-sided cardiac failure, and neurogenic disorders have been chiefly considered.

Roubier and Plauchu (1934) relate the oedema solely to hypertensive uraemia and label the condition "poumon azotémique." Other French authors adhere to this opinion (Lelong and Bernard, 1937). A similar close relation is assumed by Rendich, Levy, and Cove (1941), who, however, postulate an associated left cardiac failure.

Werkenthin (1937) suggested that a sudden failure of the left ventricle with a consequent rise of pressure in the pulmonary capillaries was the cause, perhaps associated with increased permeability due to chemical, toxic, or vasomotor influences. Similar views were expressed by Nessa and Rigler (1941). They considered that a competent right ventricle in the presence of left-sided heart failure would lead to increased pressure in the pulmonary circulation and consequent exudation into the alveoli. In addition they assumed that other general causes of oedema may be instrumental, and, referring to the experimental work of Coelho and Ribeiro (1936), they list (a) "claudication" of the left ventricle due to renal sclerosis, $(b)$ increased pulmonary venous pressure due to mitral stenosis, (c) toxic effects of neosalvarsan, iodides, and barbiturates, $(d)$ neurogenic disorders, and (e) overloading of the circulation by excessive parenteral administration of fluids. Hodson (1950) regards a failing left heart as a more convincing aetiological factor than uraemia, since two of his six cases of batswing shadow had normal levels of blood urea. These two cases showed clinically the symptoms of periarteritis nodosa. The presence of the proteinous fluid in the alveoli may be explained by the rise in intravascular pressure and damage to the capillary wall by anoxaemia.

"Centrogenic pulmonary oedema " was described by Buchtala (1950). The causes may be purely intracerebral such as trauma, operation, or epilepsy, or rapidly increasing intracranial pressure due to a subdural or extradural haematoma. On the other hand, the causative agent may be peripheral and excite a " viscero-visceral reflex." Into this group would fall those cases following sudden immersion, in which no water was aspirated, and contusion injuries to the thorax. Among the cases reported by Buchtala three had butterfly shadows. Two of these followed sudden immersion in cold water and the third after an epileptic fit.

Santé and Wyatt (1951) assume a relationship between butterfly shadows of azotaemic or antigenic oedema and collagen diseases. They 
suggest that azotaemic oedema may not be due to the raised blood level of urea and other nitrogenous metabolites. They consider that the toxic material which injures the kidney may also have a direct effect upon the interstitial tissues of the lung. They quote cases in which the typical shadowing occurred in association with renal lesions due to drug idiosyncrasies, incompatible transfusions, glomerulonephritis, and periarteritis nodosa. They therefore propose the term "antigenic pneumonitis" for the condition.

However, none of these theories is completely satisfactory. They do not explain the central distribution of the density with the translucent marginal, apical, basal, and mediastinal zones. There is no explanation of the relatively sharp margin to the shadow or of its waist-like indentation.

In a different approach to the problem Marchand (1951) showed that a prolongation of the mediastinal fascia invested the bronchi and pulmonary vessels as far as their third or fourth division. He considered that an exudate accumulating within these peribronchial and perivascular planes together with the fascia itself provided a sound anatomical explanation for the production of butterfly opacities. In experiments on cadavers radio-opaque media were injected within the planes and radiographs taken subsequently. Three examples of butterfly shadows were obtained. $\quad \mathrm{W}$ hen the medium was introduced between the pretracheal fascia and the trachea itself the radiographs showed similar but small hilar opacities in two cases out of five.

These experiments are not altogether convincing. The shadows are homogeneous whereas a method of peribronchial and perivascular infiltration might be expected to produce some streaking in the radiograph. As the injections were made under pressure it is possible that smaller vessels would be ruptured and the alveoli would fill. This condition would not necessarily be removed by the later perfusions of the pulmonary vessels.

Marchand's hypothesis is, however, notable as an attempt to explain anatomically the central localization of the butterfly opacities. In this regard it is similar to another anatomical hypothesis which was outlined by one of us a few months earlier (Herrnheiser, 1951). Both theories draw attention to the structure of the central parts of the Jung.

\section{The Anatomical Structure of the Central PARTS OF THE LUNG}

It is usual to distinguish the hilum, the central, and the peripheral parts of the lung. The generally accepted descriptions as given by Engel (1947) and shown in Fig. 5 (after Engel) are the hilum containing bronchi, vessels, nerves, and lymph nodes with connective tissue; the central area largely composeof of a dense tuft of bronchi and vessels with lung

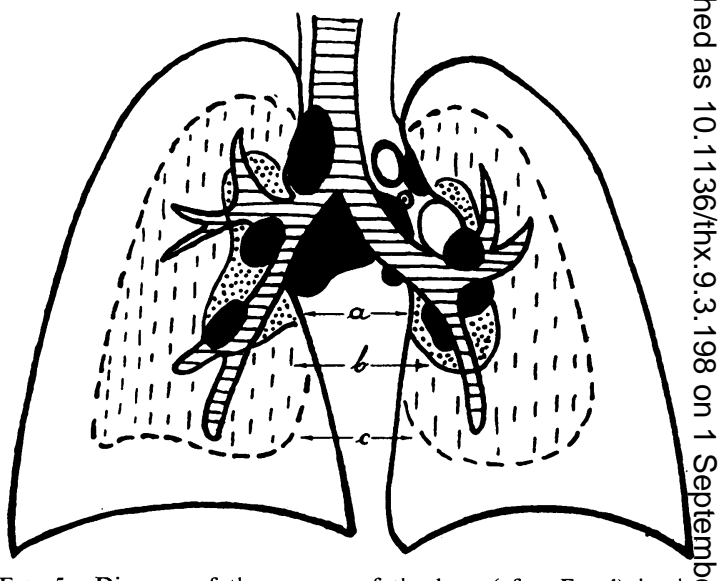

FIG. 5.-Diagram of three zones of the lung (after Engel) in theD postero-anterior view. The dotted area is the hilar zone, the hatched area the central zone, and the white area the peripherat
zone.

parenchyma in the inter-spaces; the peripherat zone consisting of respiratory tissue supplied bye bronchioles and small vessels.

The description of the central area as outlined ing Fig. 5 is satisfactory from a topographical point of view. It does not, however, convey a comprehensive picture of its intricate structure which seems to plays an essential role in the formation of butterfly opacities. This has been emphasized by Herrnheise (1951) and is founded on previous observations. (Herrnheiser, 1934; Herrnheiser and Kubat, 1936 which confirmed the general accuracy of Felix' account (1928) of the structure of a pulmonary lobex Later Herrnheiser (1942) modified Felix's originaf description as follows:

Each lobe consists of three parts: (1) a lobar root을 (2) a medulla, and (3) a cortex. It is essential to distinguish between the central and peripherat parts of the lobe and the central and peripherap parts of the lung as a whole. Unless a tiresome qualifying reference is made each time, confusiorn will arise. The terms medulla and cortex have hitherto been used for those organs such as the kidney, suprarenal, and cerebellum in which theres are anatomical and physiological differences in the two zones. Macroscopically these boundaries are obvious by the variation in colour or structure. ID is convenient to use the terms in a discussion of pulmonary lobes, as, although the boundaries are less conspicuous, there are differences both if structure and function as follows (Fig. 6):-

The root of the lobe contains no respiratory tissue and is made up of the lobar bronchus, artery, and 
veins with their primary and the proximal portions of their secondary divisions together with lymph nodes, lymphatics, ganglia, nerves, and connective tissue. The space occupied by this complex is larger than is commonly realized and its lateral outline, the boundary with the medulla (Fig. 6 , full line), is very irregular.

The medulla is composed of bronchial and vascular divisions of the second, third, and fourth orders which are accompanied in their fascial sheaths by bronchial arteries and veins, lymphatics, and nerves. Respiratory tissue is present in the interspaces. Bronchi and vessels of the fourth order, occasionally of the third and fifth, subdivide in small branches which supply the periphery (cortex) of the lobe. These divisions mark the outer border of the medulla (Fig. 6, dotted line); they are practically equidistant from each other and frequently visible in radiographs.

The respiratory tissue in the medulla consists of lobules (B.N.A.).* Felix (1928) observed on metal

* A lobule (B.N.A.) is the smallest macroscopical division of the lung tissue which is commonly separated from adjacent analogous subdivisions by connective tissue septa (interlobular septa). Confusion has arisen from Miller's description (1937) of the microscopic pulmonary unit as "primary lobule" and the previously recognized macroscopic pulmonary unit as a " secondary lobule." It appears to be inconsistent to use secondary to denote a larger respiratory unit while a secondary bronchus is of smaller calibre than a primary one. There would be no misunderstanding if lobule were used for the macroscopic division in the sense of B.N.A. and the primary lobule of Miller were known as Miller's unit.

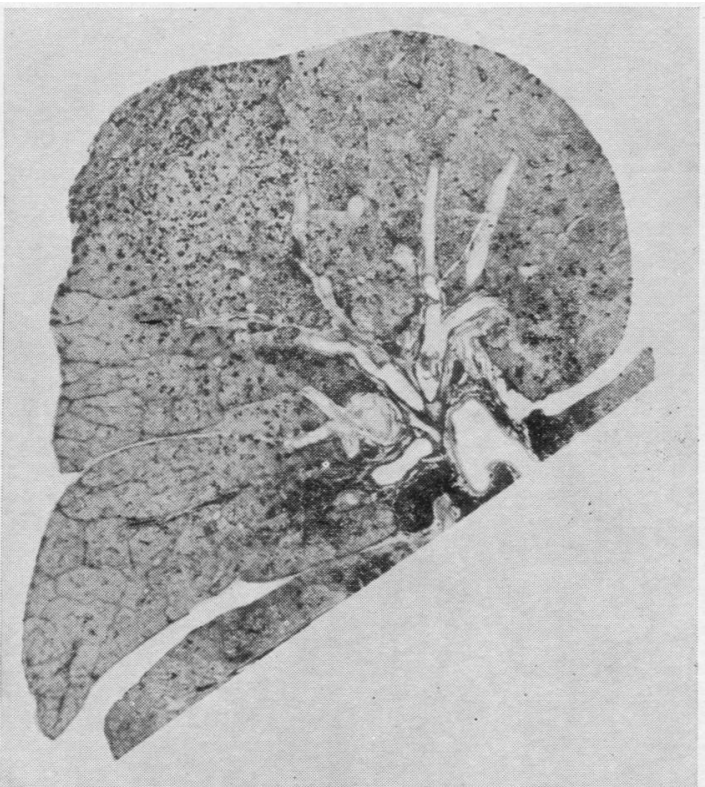

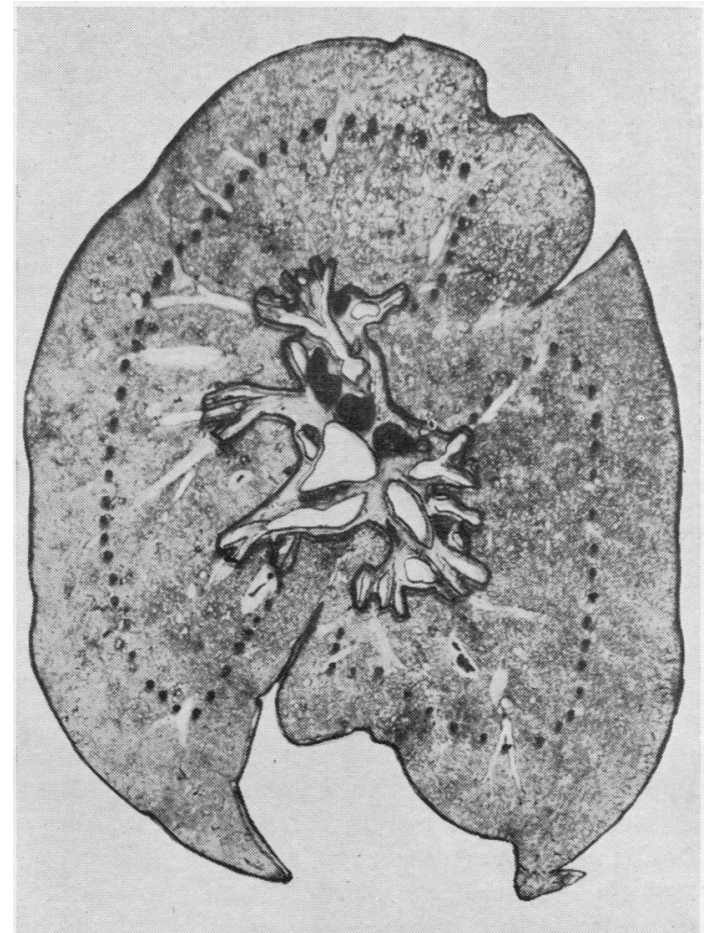

FIG. 6-Normal whole lung sections: the root, medulla, and cortex of the upper lobe and lower lobe are shown in the lateral view; antero-basal segment of lower lobe is not fully expanded. Some structures have been emphasized by carbon ink: the roots, bronchi, vessels, and lymph nodes are outlined; the boundary between root and medulla is indicated by a full line, and that between the medulla and cortex by a dotted line. Note the interlobar cortical zones extending into the central area.

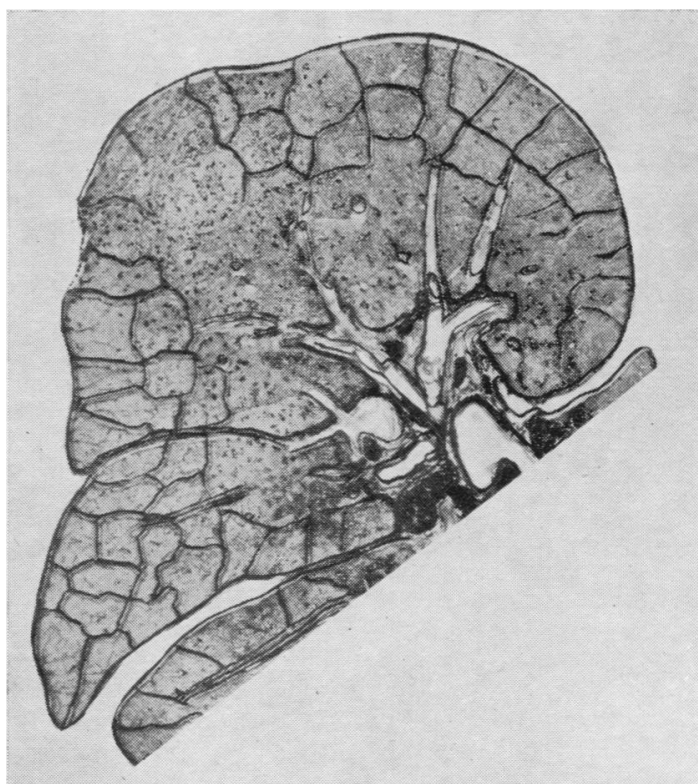

Figs. $7 a$ and $b$.-Upper lobe from whole lung section of a coal-miner's lung. Many cortical lobules are outlined by coal deposits in the interlobular septa. In Fig. $7 b$ the pigmented septa have been emphasized by carbon ink. 
casts of inflated lungs that the size of the lobules in the medulla is related to the space available between the divergent bronchi and vessels. A few small, partly developed ones arise from the distal parts of the secondary bronchi. A greater number of larger lobules arise from the third and fourth orders, but even they do not attain the complete development of those in the cortex. Deposits of carbon pigment frequently emphasize the interlobular septa on the pleural surfaces of normal lungs, but in sections of coal-miners' lungs those in the subpleural (cortical) zone (Figs. $7 \mathrm{a}, 7 \mathrm{~b}$ ) and occasionally in the medulla can be distinguished.

The cortex is $30-40 \mathrm{~mm}$. broad and envelops the whole medulla (Fig. 6). The cortical lobules were described by Felix (1928) as fully developed and occurring in an inner and outer layer. The outer lobules are typically truncated, four-sided pyramids with the base in relation to the pleura. They are 9-12 $\mathrm{mm}$. broad and $21-27 \mathrm{~mm}$. high. The inner lobules are of similar shape but smaller and shallower $(15 \times 11 \mathrm{~mm}$. $)$. Additional lobules of varying shape may be interposed between the two layers or even reach the pleura (Figs. $7 \mathrm{a}, 7 \mathrm{~b}$ ). The cortical bronchi and vessels do not normally exceed $1.5 \mathrm{~mm}$. in diameter.

Herrnheiser (1951) and Herrnheiser and Kubat (1936) have pointed out exceptions to this scheme. They have shown that the cortex is often thicker and has more than two layers in the apical and anterior segments of the upper lobes and in the lateral basal regions of the lower lobes.
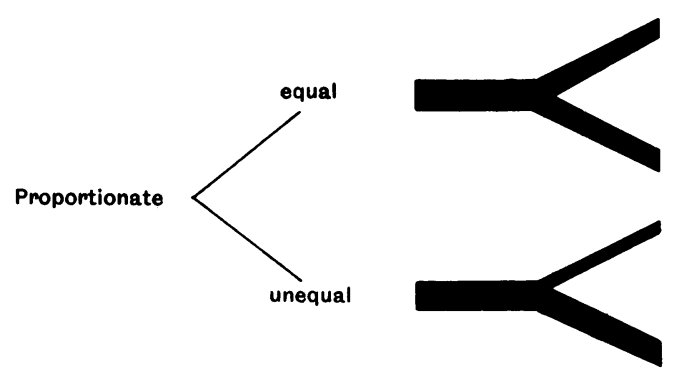

Disproportionate

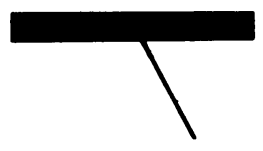

FIG. 8.-Modes of division of bronchi and vessels.
Towards the hilum and along the interlobar su्f faces the cortex is thinner and the lobules arrange्g in a single layer. The medullary area may be indent by full-sized (cortical) lobules in some place्ष, particularly between the lingula and the remainder of the upper lobe and also between the apical arfel basal segments of the lower lobes. There are als़ variations in the shape and size of lobules in the cortex (Figs. 7a, 7b). But these do not obscure thes essential differences between the cortex and medulat which are still further marked by differences in the ir bronchial and vascular supply.

From a functional point of view the arteries may be described as large or conducting, medium sizea or distributing, and small arteries and arteriols regulating the blood supply in a localized region (Bailey, 1948). The difference of function becoms evident if we compare the conducting and distribus ing arteries with "public highways" of varying

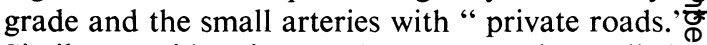
Similar considerations and names may be applied mutatis mutandis - to the veins and bronchi.

The pulmonary stems and the "lobar" vessefs and bronchi are conductive. They occur in the lobar roots only. Distributing branches are those the first to the third or fourth, in places even to the fifth orders. Branches of this category form part of the lobar root, prevail in the medulla but do nog commonly occur in the cortex. The small branches (the " private roads"), which supply a small grous of lobules or individual lobules, may be calle " prelobular" or "lobular" respectively. They a absent from the root, are regular components of the medulla and almost the only type in the cortex.

Another point of difference between medulla an cortex arises from the mode of division. The branching of bronchi has been described as dichoto. mous or monopodial and the same terms have bee applied to the vessels. Engel (1947) prefers asyms metrical dichotomy to monopodial; Hayward and Reid (1952) distinguish acute-angled and wide angled divisions. However, these descriptions take no account of differences in calibre of parent vesse and branches. If these are noted divisions can bo classified as proportionate and disproportionate. N

Proportionate divisions (Fig. 8) are those in which్c the diameter of the parent is evidently greater tha that of each single branch, but smaller than the sum of these together. The subdivisions are not always of the same width. it is suggested that proportionate divisions should be known as "equal "when the

* A similar comparison was apparently made by Havlicek (192年 as may be assumed from the title of his paper on "Vasa privata and vasa publica" (Hippokrates, 2, 105). This article is mentioned witl out quotation in another publication of Havlicek (1934). We have been unable to see the first of these journals. 
FIG. 9.-Dissection of an injected pulmonary artery. Note the numerous small branches arising from disproportionate divisions, some indicated by arrows.

diameters of the branches are practically the same, but if their diameters are different, varying up to as much as one is to three, they should be known as "unequal."

Disproportionate divisions (Fig. 8) are those in which the calibre of the branches is strikingly different. The larger branch is obviously a continuation of the parent whose diameter is not visibly reduced after the smaller branch has arisen; the latter is only a small fraction in width. The small branches are easily overlooked and pruned in the preparation of injected specimens. They are demonstrable in casts (Herrnheiser, 1936), in dissections of injected vessels (Fig. 9), microscopically (Fig. 10), or radiographically (Figs. 11, 12). Monopodial divisions are usually disproportionate.

In the medulla the great majority of the small lobular or prelobular branches arises from disproportionate divisions, which occur throughout from the second order branches onwards; they supply either an individual lobule or a small group. The medium-sized distributing vessels and bronchi undergo proportionate divisions and consequently increase in numbers, but diminish progressively in diameter towards the cortex. At the outer border of the medulla they divide into small branches which enter the cortex.

FIG. 10.-Vessel with two disproportionate branches. Section from near the outer boundary of the medulla, $\times 120$.

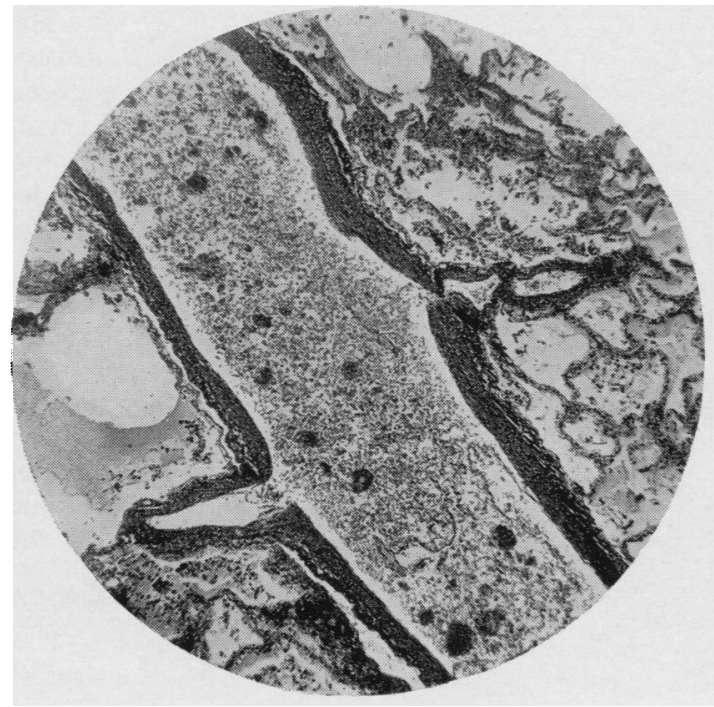

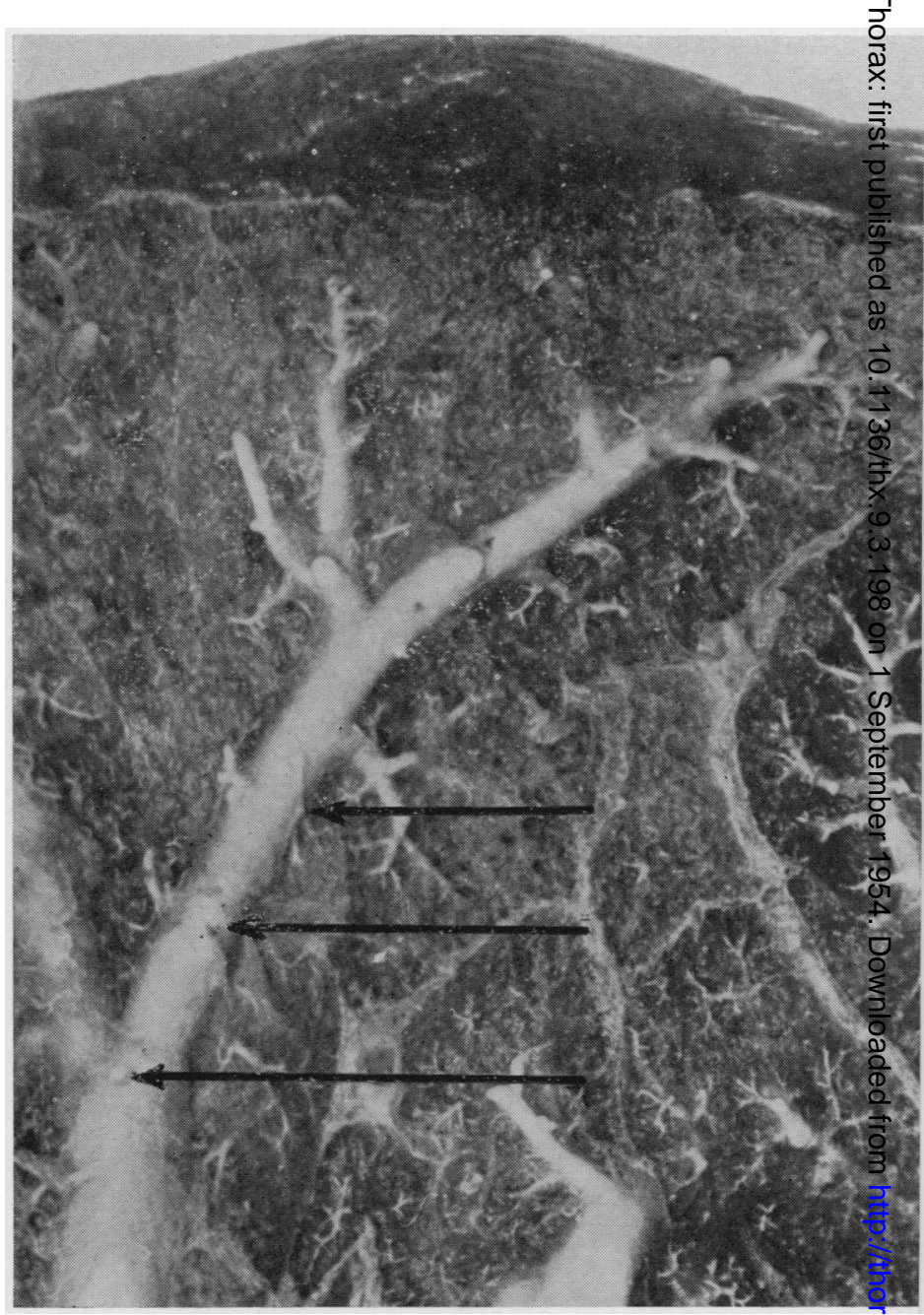

Within the cortex the majority of the prelobular and lobular branches are formed from proportionate divisions. Only in the interlobar and mediastinal areas of the cortex are many lobules supplied from disproportionate divisions arising earlier in the medulla.

The anatomical differences of medulla and cortex are summarized in Table I. The areas occupied by the root, medulla, and cortex of each lobe are schematically outlined in the diagrams Figs. 13 and Fig. 14.

Examining the whole lung on either side it is evident from Fig. 6 and Figs. 13 and 14 that the peripheral zone of the lung is uniformly composed of cortical parenchyma. The central area of the lung is, however, complex in structure and contains not only the root and medulla of each lobe but also interlobar and mediastinal portions of the cortex. Such differences may be associated with variations in functional response. 


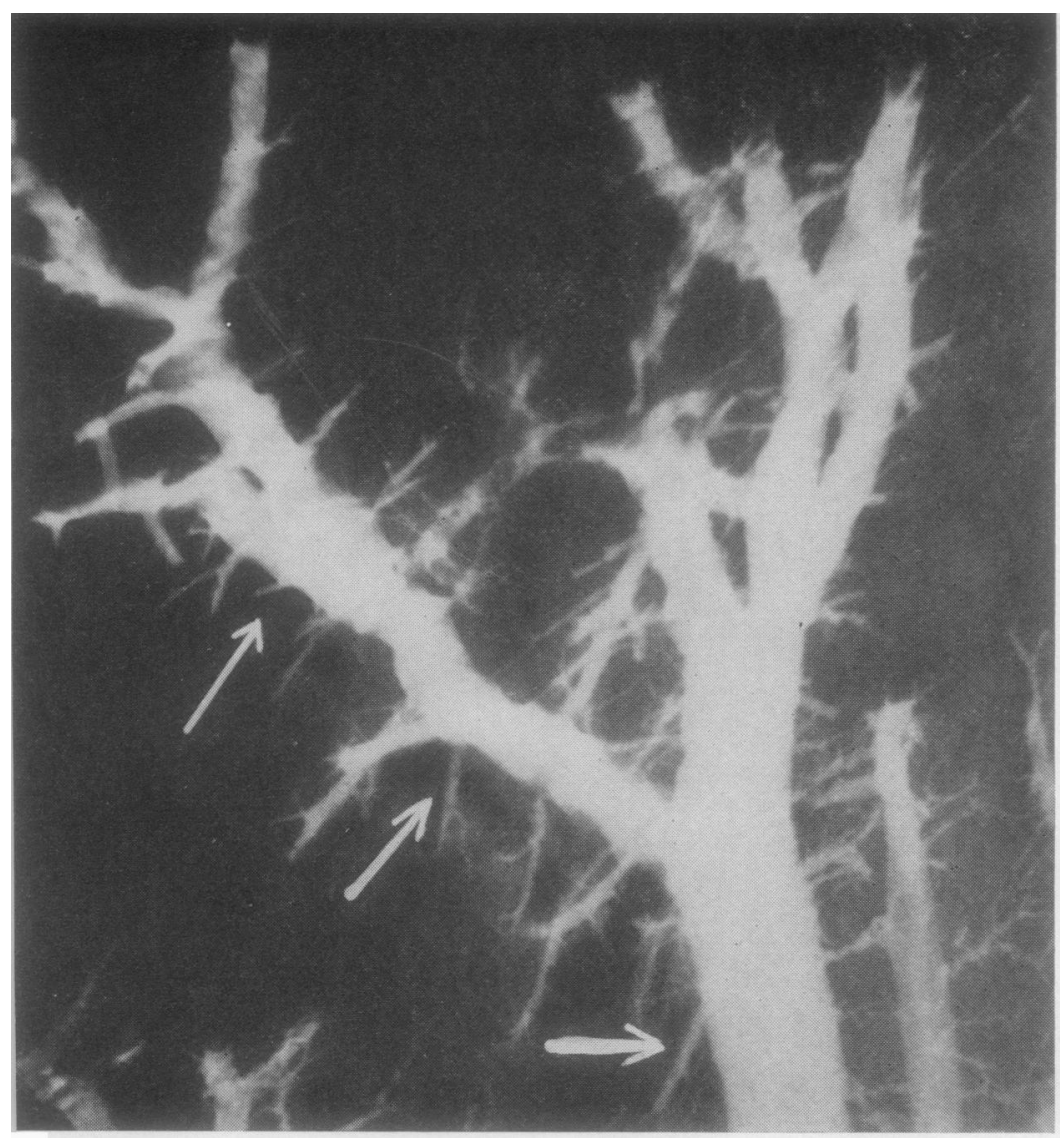

FIG. : 11.-Radio-opaque injection of a segmenta artery. Numerous disproportionate branches in the medullary area, some indicated by arrows.

FIG. 12.-Radio-opaque injection of a segmental vein. Numerous disproportionate branches in the medullary area, some indicated by arrows.
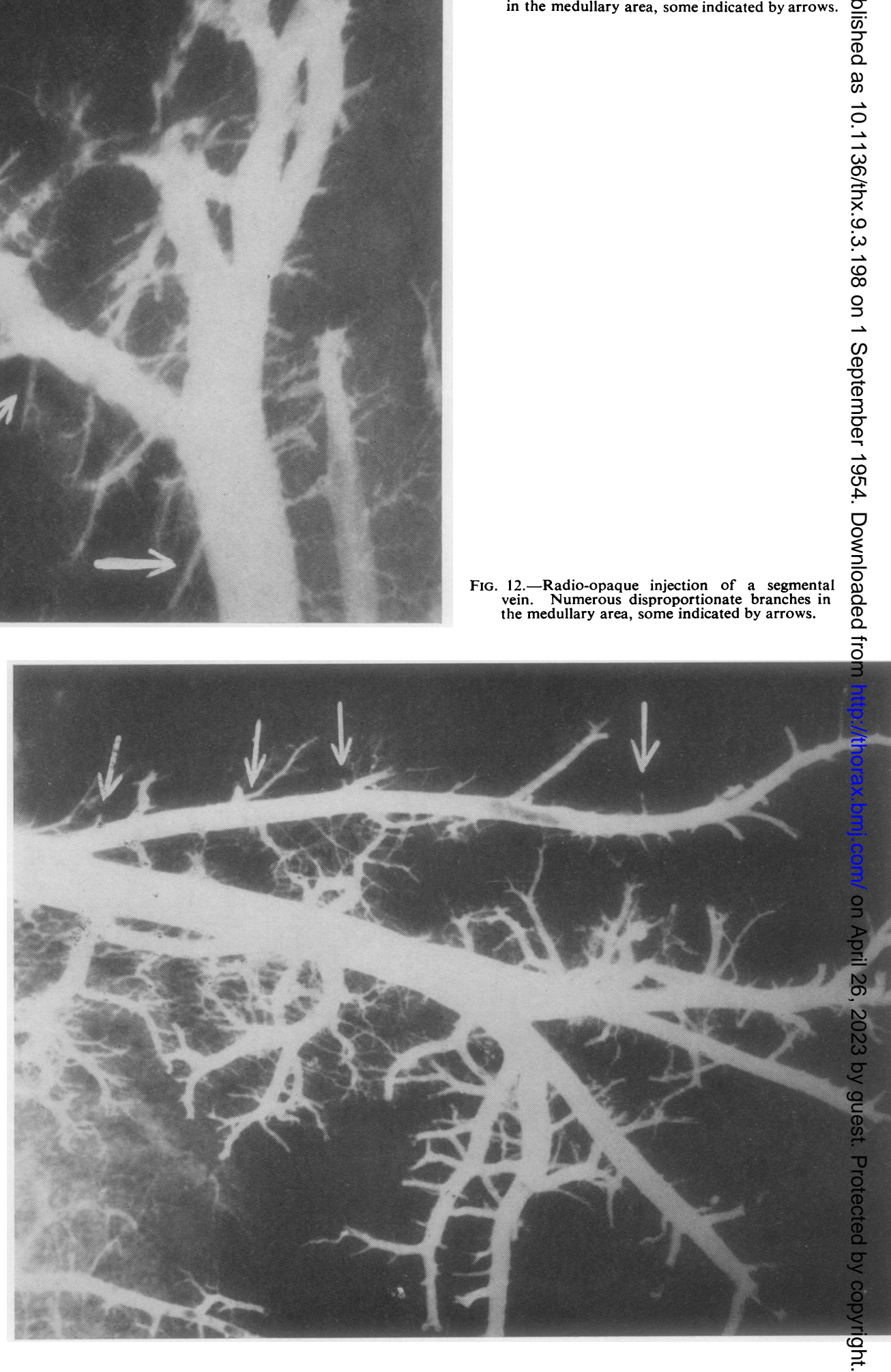
TABLE I

ANATOMICAL DIFFERENCES BETWEEN THE ROOT, THE MEDULLARY, AND CORTICAL PARTS OF THE LOBES

\begin{tabular}{|c|c|c|c|}
\hline & Root & Medulla & Cortex \\
\hline Topography & Hilar region & $\begin{array}{l}\text { Interior of } \\
\text { lobe }\end{array}$ & $\begin{array}{l}\text { Periphery of } \\
\text { lobe envel- } \\
\text { oping the } \\
\text { medulla }\end{array}$ \\
\hline Respiratory parenchyma & None & $\begin{array}{c}\text { Placed be- } \\
\text { tween the } \\
\text { diverging } \\
\text { bronchial } \\
\text { and vascu- } \\
\text { larbranches }\end{array}$ & $\begin{array}{l}\text { Chief com- } \\
\text { ponent }\end{array}$ \\
\hline Lobules (B.N.A.) & None & $\begin{array}{l}\text { Not fully } \\
\text { sized, in } \\
\text { p l a c es } \\
\text { poorly de- } \\
\text { veloped }\end{array}$ & $\begin{array}{l}\text { M a jority } \\
\text { fully deve- } \\
\text { loped, some } \\
\text { exceptions }\end{array}$ \\
\hline $\begin{array}{l}\text { Bronchi and vessels } \\
\text { 1. Large conducting (lobar } \\
\text { bronchus, artery and } \\
\text { veins) }\end{array}$ & $\begin{array}{l}\text { In the root } \\
\text { only }\end{array}$ & None & None \\
\hline $\begin{array}{l}\text { 2. Medium sized distribu- } \\
\text { ting branches of } 1 \mathrm{st}-4 \text { th } \\
\text { (5th) order }\end{array}$ & $\begin{array}{l}\text { 1st order } \\
\text { and proxi- } \\
\text { mal parts } \\
\text { of } 2 \text { nd } \\
\text { order }\end{array}$ & $\begin{array}{l}\text { 2nd }-4 \text { th } \\
\text { (5th) order } \\
\text { prevailing }\end{array}$ & $\begin{array}{l}\text { Not com- } \\
\text { monly }\end{array}$ \\
\hline $\begin{array}{l}\text { 3. Small prelobular or } \\
\text { lobular branches arising } \\
\text { from } \\
\text { (a) proportionate divi- } \\
\text { sions }\end{array}$ & None & $\begin{array}{l}\text { Less } \\
\text { frequent }\end{array}$ & $\begin{array}{l}\text { Great } \\
\text { majority }\end{array}$ \\
\hline $\begin{array}{l}\text { (b) disproportionate } \\
\text { divisions }\end{array}$ & None & Numerous & $\begin{array}{l}\text { Less fre- } \\
\text { quent (ex- } \\
\text { ceptions: } \\
\text { interlobar } \\
\text { and medi- } \\
\text { astinal re- } \\
\text { gion) }\end{array}$ \\
\hline
\end{tabular}

The Formation of Butterfly Shadows

A radio-opaque lesion in both lungs, occupying the medullary areas alone, must produce the typical picture of a butterfly'-shaped opacity. This follows from the laws of radiological projection and is evident from the Figs. 13 and 14.

A localization of this kind can completely explain what Doniach (1947) has called the enigma of butterfly shadows. The bilateral confinement of the lesion to the medullary areas will be responsible for the typical form and the central site of the opacity. That the cortex is not involved accounts for the translucent marginal zones, for the waist-like indentation along an interlobar fissure, and for the clear mediastinal areas. Atypical cases may be easily explained in a similar way. They may be due to an incomplete (unilateral, unilobar, or even segmental) involvement of the medullary areas; or, on the other hand, they may be due to an involvement of cortical parts either by radio-opaque complications or by the underlying lesion encroaching upon the cortex.

We suggest, therefore, that the formation of butterfly shadows depends essentially upon the

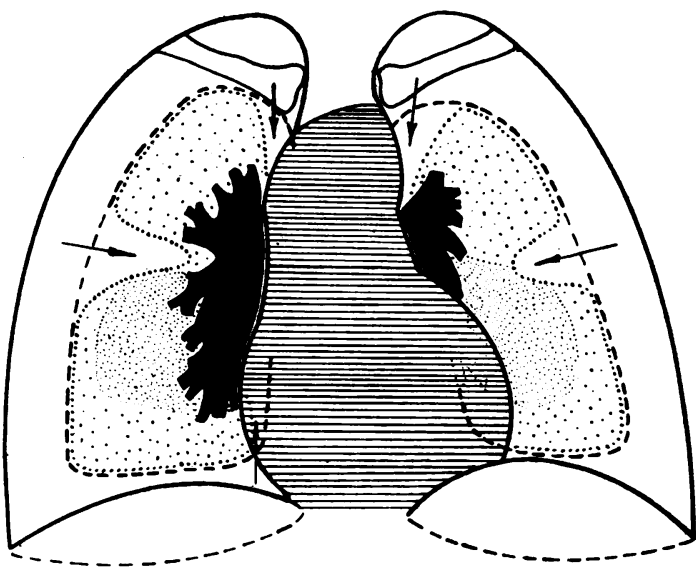

Fig. 13.-Diagram of lobar roots, medulla, and cortex as seen from the front (postero-anterior projection). Black areas: lobar roots and hilum. Sparsely dotted areas: medulla. Densely dotted areas: overlapping of the lower lobe medulla by medulla of either middle lobe or lingula. Dotted outline: boundary of either middle lobe or lingula. Dotted outline: boundary
between medulla and cortex. Interrupted outline: boundary between peripheral and central areas after Engel. White areas: cortex. Arrows showing cortex extending between and into meduliary area.

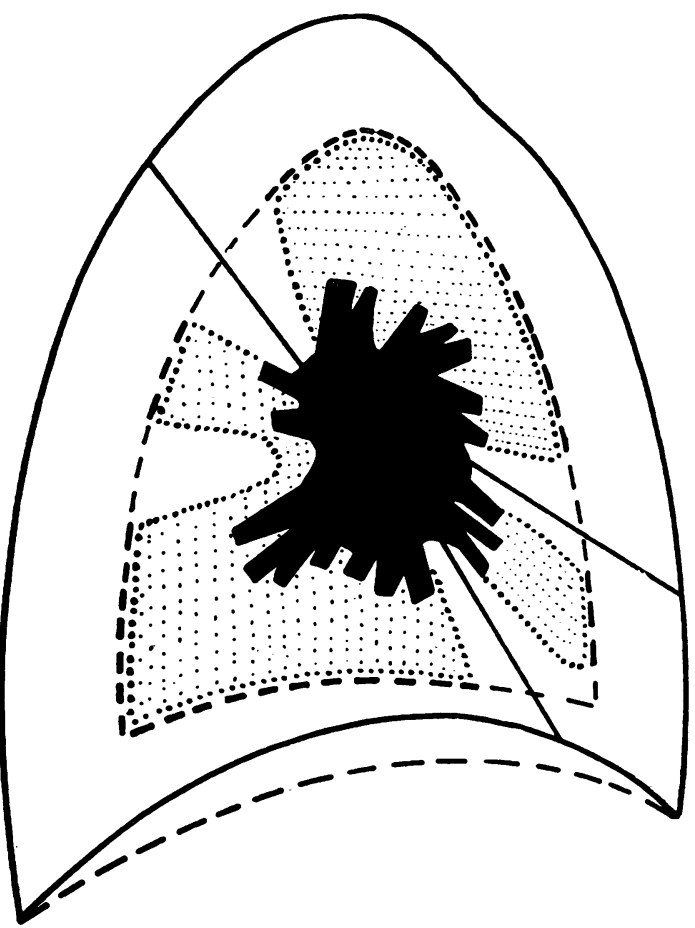

FIG. 14.-Diagram of the right lobar roots, medulla, and cortex seen from the side. Overlapping by the left lung is not shown. Key to diagram as in Fig. 13. 


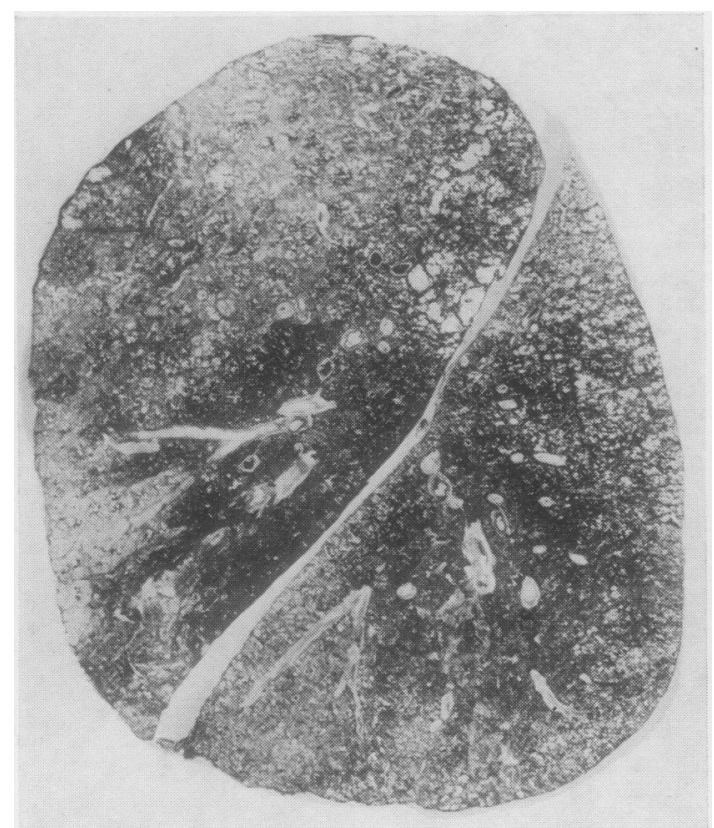

FIG. 15.-Whole section of the left lung (Case 4, Fig. 4; unstained). Lower lobe: the whole medulla occupied by haemorrhagic exudation, the cortex almost free. Upper lobe: haemorrhagic exudation involving medulla of lingular segment but also encroaching upon the interlobar cortex of the lingula.

medullary distribution and not upon the specific nature of the underlying changes. We further suggest that this distribution is conditioned by differences in the anatomical structure of the lobar medulla and cortex.

The butterfly distribution of a pulmonary lesion may, however, not be readily demonstrable in necropsy specimens. The changes are frequently obscured by terminal complications such as pneumonia, or they clear completely or almost completely before death. In addition, the conventional dissection of collapsed lungs does not properly display the distribution even of actual butterfly lesions. Satisfactory results can be obtained with the whole section technique of Gough and Wentworth (1949) which we were able to use in two cases (Figs. 15 and 16 ).

The whole sections of these two cases confirmed our suggestion. One case (Fig. 15) with a marked butterfly shadow lasting until death showed a haemorrhagic exudation occupying the whole medulla of the lower lobe and of the lingula. The cortex of the lower lobe and of most of the upper lobe remained practically free; the exudation encroached only upon the interlobar area of the lingular cortex. In the other case (Fig. 16) the butterfly opacity had almost disappeared before
FIG. 16.-A whole section of right lung (Case 1, Figs. $1 a$ and unstained). Lower and middle lobes; terminal bronchopneumonif The butterfly opacity had disappeared before death. Uppe lobe: in the inner parts of the medulla and the angles betwe large bronchi and vessels, residues of the butterfly lesion persist (arrows).

death and a bilateral terminal pneumonia hağ developed. A residue of the butterfly lesion wass however, still there in the form of scanty haemot rhagic oedema and was localized in the medulia of the upper lobe.

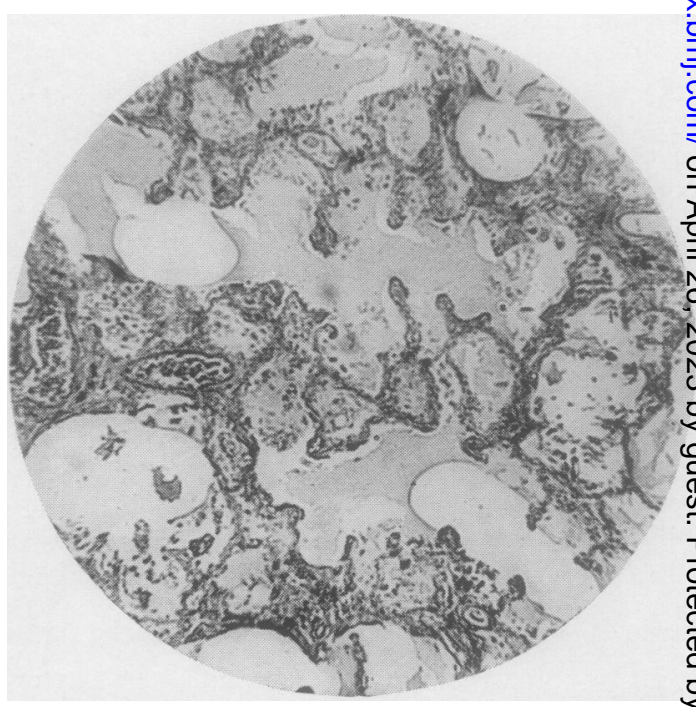

FIG. 17.-Scanty haemorrhagic pulmonary oedema (Case 1). 
The medullary localization of butterfly lesions is thus established by the anatomical findings and our explanation of their radiological appearances is confirmed. The occurrence of the lesion in the medulla may be explicable on physiological grounds.

it seems very probable that the structural differences between medulla and cortex are associated with differences in function. This suggestion is supported by the angiographic investigations of Goodwin, Steiner, and Lowe (1952) which showed that in some types of mitral stenosis the circulatory conditions in the lung periphery are different from those in the centre. The variations of the pulmonary vessels in calibre and in mode of division are striking. These, together with the histological structure of the middle-sized distributing arteries and of the small arteries, point to physiological differences. The small arteries are particularly adapted for vasoconstriction and vasodilatation which alters the peripheral resistance to flow from the larger arteries and hence they play an important part in regulating the blood pressure (Bailey, 1948). From the small vessels there also arise numerous precapillary anastomoses between the pulmonary arteries and veins and between the pulmonary and bronchial arteries (Tobin and Zariquiey, 1953) in both of which "shunting" may occur.

In this context it may be significant that the distributing vessels are chief components of the medulla but not of the cortex. On the other hand, it may be important that small branches arising from proportionate divisions prevail in the cortex as against the preponderance of disproportionate branches in the medulla. We assume that these anatomical differences lead to functional conditions which favour an early and almost exclusive occurrence of exudate in the medulia. The frequent involvement of interlobar or mediastinal areas of the cortex is explained by the fact that these areas are partly supplied from small disproportionate vessels.

A definite description of the functional mechanism cannot yet be given. Various hypotheses may be considered such as increased pressure in pulmonary veins due to left ventricular failure, or neurogenic factors, or Kerley's (1950) suggestion of shunts similar to shunts in kidneys described by Trueta, Barclay, Franklin, Daniel, and Prichard (1947). However, the basic physiological investigations on the pulmonary circulation are still in such an early stage and so controversial that no detailed conclusions can be safely drawn. Whatever the final functional explanation may be our observations suggest that it will have to be based upon anatomical-functional differences between the lobar medulla and cortex.

\section{SUMmarY}

The radiological features of typical and atypical butterfly shadows in the lungs are briefly described. The literature is reviewed and the various hypotheses of pathogenesis are discussed, none of which satisfactorily explains the enigma of butterfly opacities.

A new explanation is suggested based upon previous anatomical investigations on the structure of lung lobes and upon new evidence from whole lung sections and from injected pulmonary vessels. It is demonstrated that each lobe consists of three parts: (1) the lobar root, (2) the medulla (inner part) enveloped by (3) the cortex (outer part). The topographic and structural differences of these parts are shown and attention is drawn to the different mode of division from which the small (prelobular and lobular) bronchi and vessels arise. In the cortex, except in certain interlobar and mediastinal areas, proportionate divisions prevail, whereas in the medulla most divisions are disproportionate.

All radiological appearances of butterfly opacities can be completely explained by the occurrence of radio-opaque lesions which are practically confined to the medulla alone. That the cortex is not involved will account for the translucent marginal zones, the waist-like indentations, and the clear mediastinal areas. It is, therefore, suggested that the formation of butterfiy shadows depends essentially upon the medullary distribution and not upon the specific nature of the underlying changes. The medullary localization of butterfly lesions has been confirmed in whole lung sections in two fatal cases.

It is further suggested that there is a correlation of the structural and functional differences between medulla and cortex and that this may lead to conditions which favour an early and almost exclusive exudation in the medulla.

We are indebted to Mr. J. T. Fathi, Dr. I. Gordon, and Dr. A. A. Lewis for permission to study cases under their care. Dr. H. Caplin and Dr. F. Marsh kindly supplied necropsy specimens.

We also wish to thank Dr. S. Engel for permission to reproduce his diagram (Fig. 5).

\section{REFERENCES}

Bailey, F. (1948). Bailey's Textbook of Histology, 12th ed., revised by P. E. Smith and W. M. Copenhaver. Baillière, Tindall and

Buchtala, V. (1950). Fortschr. Röntgenstr., 73, 702.

Coe, F. O., and Otell, L. S. (1932). Amer. J. Roentgenol., 27, 101. Coelho, E., and Ribeiro, M. (1936). Arch. Mal. Coeur., 29, 383.

Day, H. F., Sisson, W. R., and Vogt, E. C. (1929). Amer. J. Roentgenol., 22, 349 .

Doniach, I. (1947). Ibid., 58, 620.

Engel, S. (1947). The Child's Lung. Arnold, London.

Felix, W. (1928). In Sauerbruch, F. Die Chirurgie der Brustorgane, Vol. I, Pt. 1, 3rd ed. Berlin.

Goodwin, J. F., Steiner, R. E., and Lowe, K. G. (1952). J. Fac. Radiol., Lond., 4, 21 . 
Gough, J., and Wentworth, J. E. (1949). J. roy. micr. Soc., 63, 231. Havlicek, H. (1934). Bruns' Beitr. klin. Chir., 160, 174

Hayward, J., and Reid, L. McA. (1952). Thorax, $7,89$.

Hernheiser, G. (1934). IVth Int. Congr. Radiol., Zurich, vol. 2, p. 17.

- (1942). Amer. J. Roentgenol., 48, 595.

- and Kubat, A. (1936). Z. Anat. EntwGesch., 105, 570.

Hodson, C. J. (1950). J. Fac. Radiol., Lond., 1, 176.

Kerley, P. (1950). Ibid., 1, 143

Lelong, M., and Bernard, J. (1937). Bull. Soc. Mid. Hôp. Paris, 53,177

Marchand, P. (1951). Thorax, 6, 359

M iller, W.' S. (1937). The Lung. Springfield, Ill

Nessa, C. B., and Rigler, L. G. (1941). Radiology, 37, 35

Prichard, M. M. L.. Daniel, P. M., and Ardran, G. M. (1954). Brit. J. Radiol., $27,93$.

Rendich, R. A., Levy, Roentgenol., 46, 802.

Roubier, C. (1938). J. Méd., Lyon, 19, 467.

- and Plauchu, M. (1933). Lvon méd., 152, 137.

-_-_(1934), Arch. méd.-chir. Appar. resp., 9, 189.

Santé, L. R., and Wyatt, J. P. (1951). Amer. J. Roentgenol 66, 527 Tobin. C. E., and Zariquiey, M. O. (1953). Med. Radiogr. Photogr. $29,9$.

Trueta, J., Barclay, A. E.. Franklin, K. J., Daniel, P. M., and Prichard, M. M. L. (1947). Studies of the Renal Circulation. London.

Werkenthin, M. (1939). Amer. J. Roentgeriol., 41, 183.

Zdansky, E. (1933). Röntigenpraxis., 5, 248.

\section{AdDENDUM}

Since this article was completed, Prichare Daniel, and Ardran (1954) have published an account of angiographic and anatomical findings the lungs of small animals which confirms our observations in man. They describe and illustrate peripheral ischaemia under experimental conditiond and demonstrate by means of casts the sma $\Phi$ branches arising directly from the larger pulmonar arteries and veins.

They also confirm that blood can pass from the pulmonary arteries to the pulmonary venous syster $\vec{\infty}$ through the deeper parts of the lung without the necessity for circulation through the periphera portion, and suggest that such conditions pulmonary blood flow may be concerned with the production of butterfly opacities. 